01.1;05.1

\title{
Влияние предварительного динамического нагружения на усталостную долговечность сплава АМг6
}

\author{
() Д.А. Билалов ${ }^{1,2}$, В.А. Оборин ${ }^{2}$, О.Б. Наймарк ${ }^{2}$, М.В. Нарыкова ${ }^{1,}$, А.Г. Кадомцев ${ }^{1}$, В.И. Бетехтин ${ }^{1}$ \\ ${ }^{1}$ Физико-технический институт им. А.Ф. Иофффе РАН, Санкт-Петербург, Россия \\ ${ }^{2}$ Институт механики сплошных сред УрО РАН, Пермь, Россия \\ I E-mail: Maria.Narykova@mail.ioffe.ru
}

Поступило в Редакцию 6 ноября 2019г.

В окончательной редакции 6 ноября 2019 г.

Принято к публикации 30 января 2020г.

\begin{abstract}
Проведено экспериментальное исследование влияния предварительного динамического нагружения на предел выносливости сплава АМг6 на базе $10^{9}$ циклов. Показано, что при деформировании до величины деформации $10 \%$ со скоростью деформации $10^{3} \mathrm{~s}^{-1}$ предел выносливости уменьшается на $22 \%$. Предложена математическая модель, которая способна адекватно предсказывать усталостное разрушение, в том числе после предварительного нагружения.
\end{abstract}

Ключевые слова: гигацикловая усталость, численное моделирование, разрушение, предел выносливости.

DOI: 10.21883/PJTF.2020.08.49309.18098

Детали машин и элементы конструкций в процессе эксплуатации испытывают в большинстве случаев циклические нагружения с амплитудами ниже предела прочности. Это приводит в конечном итоге к усталостному разрушению иногда даже после нескольких циклов нагружения. Выделяют мало-, много- и гигацикловую усталость. При гигацикловой усталости прикладываемые напряжения ниже предела текучести и материал выдерживает около $10^{8}-10^{10}$ циклов до разрушения. Ключевой особенностью разрушения в режиме гигацикловой усталости является зарождение очага разрушения в объеме образца, причем в отличие от малои многоцикловой усталости бо́льшая часть времени разрушения уходит на образование, а не на рост усталостной трещины [1]. Данные факты делают подобный вид разрушения наиболее опасным ввиду сложности диагностики. В связи с этим возникает потребность прогнозирования усталостной долговечности материалов на базе $10^{9}$ циклов.

Актуальной задачей также является предсказание снижения предела выносливости после случайных нагрузок [2,3], например после предварительного динамического нагружения. Применительно к авиамоторостроению примерами таких ситуаций могут служить попадание птиц в турбину двигателя или соударение с камнями и прочими мелкими частицами при взлете самолета.

Задача оценки усталостной долговечности и предела выносливости возникает на этапе проектирования конструкции, которая должна быть изготовлена из материалов с заранее известными физико-механическими свойствами. Экспериментальное построение кривых Велера, отражающих зависимость числа циклов до разрушения от амплитуды приложенных напряжений, не дает исчерпывающей информации для прогнозирования долговечности конструкции. Это связано с тем, что данные испытания проводятся на образцах определенной геометрии при одноосном нагружении. В реальной конструкции, как правило, реализуется сложное многоосное напряженно-деформированное состояние. Кроме того, существенную роль играет масштабный эффект, согласно которому предел выносливости может зависеть от размера образцов для усталостных испытаний. Все это усложняет процесс переноса данных, полученных для лабораторных образцов, на реальную конструкцию. В связи с отмеченным выше в дополнение к экспериментальным исследованиям возникает потребность разработки теории, которая была бы способна на основе экспериментальных данных предсказывать усталостное разрушение при произвольном нагружении.

Цель нашего исследования - разработка математической модели, которая способна адекватно предсказывать разрушение металлов и сплавов при гигацикловой усталости, а также снижение предела выносливости после предварительных динамических нагрузок.

В качестве материала для исследования выбран сплав АМг6, который находит применение в авиастроении [4]. Сплав АМг6 применяется для внутреннего набора самолетов, сварных емкостей [5] и топливных баков [4], обладает высокой конструктивной прочностью, выносливостью, высокой коррозионной стойкостью $[6,7]$.

Усталостные испытания образцов специальной геометрии (рис. 1) проводились на машине Shimadzu USF-2000 с частотой $20 \mathrm{kHz}$ и коэффициентом асимметрии $R=-1$. Предварительное динамическое нагружение с характерными скоростями деформации $10^{3} \mathrm{~s}^{-1}$ и величиной пластической деформации $\sim 10 \%$ осуществлялось на разрезном стержне Гопкинсона-Кольского [8,9].

Экспериментальные $S-N$-диаграммы представлены на рис. 2. Полученные результаты изучения усталостного 


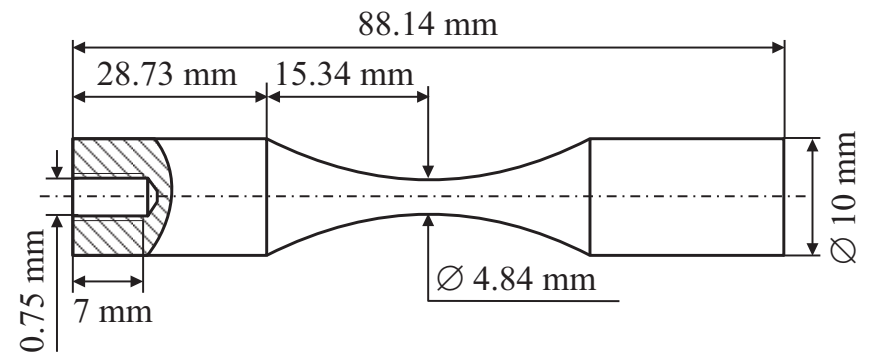

Рис. 1. Геометрия образцов для усталостных испытаний.

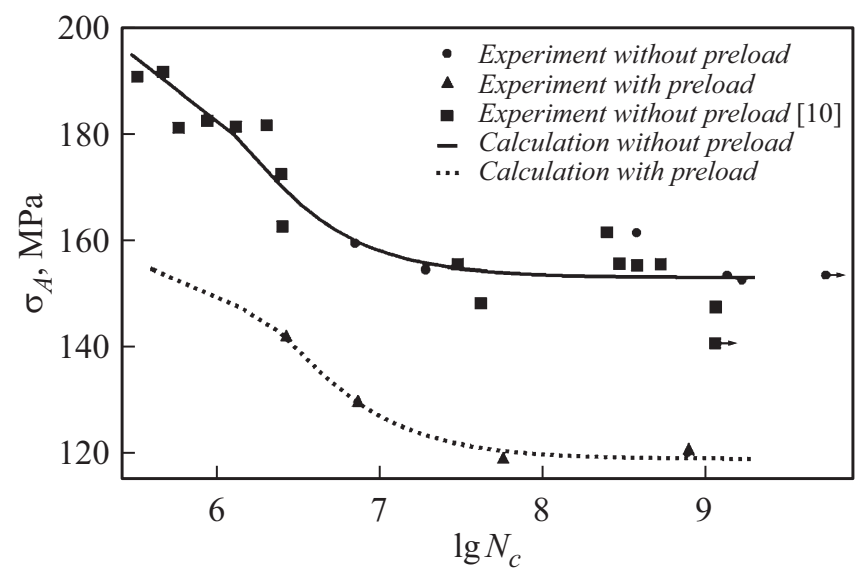

Рис. 2. Экспериментальные и расчетные кривые Велера $(S-N$-диаграммы).

разрушения без предварительного динамического нагружения хорошо согласуются с данными других исследователей [10]. Показано, что предварительное деформирование до величины пластической деформации $\sim 0.1$ с характерной скоростью деформации $10^{3} \mathrm{~s}^{-1}$ снижает предел выносливости на базе $10^{9}$ циклов для сплава АМг6 на 22\% (со 154 до $120 \mathrm{MPa}$ ).

Определяющие соотношения, учитывающие накопление поврежденности [11], используемые для прогнозирования усталостного разрушения, в трехмерном случае имеют следующий вид:

$$
\begin{gathered}
\dot{\varepsilon}^{p}=\dot{\varepsilon}_{0}^{n_{\varepsilon}}\left(\Gamma_{\sigma} \boldsymbol{\sigma}_{d}-\Gamma_{p \sigma} \frac{\partial F}{\partial \mathbf{p}}\right) \\
\dot{\mathbf{p}}=\dot{\varepsilon}_{0}^{n_{p}}\left(\Gamma_{p \sigma} \boldsymbol{\sigma}_{d}-\Gamma_{p} \frac{\partial F}{\partial \mathbf{p}}\right) \\
\dot{\delta}=-\dot{\varepsilon}_{0}^{n_{\delta}} \Gamma_{\delta} \frac{\partial F}{\partial \delta} \\
\frac{F}{F_{m}}=\frac{p^{2}}{2}-\frac{p^{2}}{2 \delta}+c_{1} p+c_{2} \ln \left(c_{3}+c_{4} p+p^{2}\right)-\frac{\boldsymbol{\sigma}_{d}: \mathbf{p}}{2 G}
\end{gathered}
$$

В (1)-(4) введены следующие обозначения: $\varepsilon^{p}-$ тензор пластических деформаций; $\dot{\varepsilon}_{0}-$ характерная скорость деформации; $\Gamma_{\sigma}, \Gamma_{p \sigma}, \Gamma_{p}, \Gamma_{\delta}-$ положительные кинетические коэффициенты; $\boldsymbol{\sigma}_{d}-$ девиаторная часть тензора напряжений; $F-$ неравновесная свободная энергия; p - тензор плотности микродефектов типа трещин, нано- и микропор; $p=\sqrt{\mathbf{p}: \mathbf{p}} ; n_{\varepsilon}, n_{p}, n_{\delta}-$ константы, отвечающие за скоростную чувствительность материала; $\delta=\left(r / r_{0}\right)^{3}$ - параметр структурного скейлинга, $r$ - расстояние между дефектами, $r_{0}$ - размер дефектов; $G$ - модуль сдвига; $F_{m}, c_{1}-c_{4}-$ константы аппроксимации. Значения параметров модели для сплава АМг6: $\Gamma_{\sigma}=529(\mathrm{~Pa} \cdot \mathrm{s})^{-1}, \Gamma_{p \sigma}=38.5(\mathrm{~Pa} \cdot \mathrm{s})^{-1}$, $\Gamma_{p}=2.9(\mathrm{~Pa} \cdot \mathrm{s})^{-1}, \Gamma_{\delta}=3.46(\mathrm{~Pa} \cdot \mathrm{s})^{-1}, n_{\varepsilon}=n_{p}=0.967$, $n_{\delta}=1.985, G=27 \mathrm{GPa}$.

При моделировании использовался критерий разрушения $\delta \leqslant \delta_{c} \approx 0.4$. Смысл данного критерия заключается в том, что размер дефектов в материале достигает некоторого критического значения. Начальные условия для пластических и структурных деформаций соответствовали недеформированному состоянию: $\varepsilon^{p}=0, p=0$. Начальное значение параметра структурного скейлинга было задано $\delta=1.15$, что соответствует типичному пластичному материалу. Условие нагружения задавалось в виде гармонического закона $\sigma=\sigma_{A} \sin (\omega t), t-$ время, $\omega=2 \pi v, v=20 \mathrm{kHz}$ - частота нагружения. Для определения начальных условий после предварительного нагружения решалась соответствующая задача динамического деформирования. Таким образом, для прогнозирования усталостного разрушения после динамического нагружения использовались начальные условия вида $\varepsilon^{p}=0.09, p=0.01, \delta=1.05$.

Предложенная математическая модель способна адекватно предсказывать усталостное разрушение сплава АМг6, в том числе после предварительного динамического нагружения (рис. 2). Модель также описывает эффект дуальности кривой Велера, выраженный в изменении угла наклона $S-N$-диаграммы в логарифмических координатах при переходе от много- к гигацикловой усталости. Определяющие соотношения (1)-(4) записаны для трехмерного случая, поэтому с их помощью можно прогнозировать деформационное поведение и разрушение в ситуациях с произвольным многоосным напряженно-деформированным состоянием. В перспективе предложенная модель, встроенная в пакеты прикладных программ, может быть использована для прогнозирования усталостной долговечности конструкций.

\section{Финансирование работы}

Bce проведенные исследования выполнены за счет гранта Российского научного фонда (проект № 19-12-00221).

\section{Конфликт интересов}

Авторы заявляют, что у них нет конфликта интересов. 


\section{Список литературы}

[1] Plekhov O., Prokhorov A., Naimark O., Narykova M., Kadomtsev A., Betechtin V. // Eng. Fracture Mech. 2016. V. 167. P. 273-283.

[2] Hanschke B., KlaukeT., Kuhhorn A. // Proc. of the ASME Turbo Expo: Turbine Technical Conference and Exposition. 2017. V. 7A-2017. P. 130041.

[3] Witek L., Bednarz A., Stachowicz F. // Eng. Fail. Anal. 2015. V. 58. P. 229-237. DOI: 10.1016/j.engfailanal.2015.09.002

[4] Фридляндер И.Н. // МиТОМ. 2002. № 7. С. 24-29.

[5] Фетисов Г.П., Духновский Д.А. // Проблемы черной металлургии и материаловедения. 2017. № 1. С. 102-104.

[6] Жмуйдин Н.С., Бем Е.А., Гришков Д.Е., Назаров С.В. // Актуальные проблемы авиации и космонавтики. 2018. Т. 1. № 14. C. 432-433.

[7] Шибков А.А., Золотов А.Е., Желтов М.А., Михлик Д.В., Кочегаров С.С. // Вестн. Тамбов. ун-та. Сер. Естественные и технические науки. 2016. Т. 21. № 3. С. 1440-1443. DOI: $10.20310 / 1810-0198-2016-21-3-1440-1443$

[8] Оборин В.А., Банников М.В., Баяндин Ю.В., Соковиков М.А., Билалов Д.А., Наймарк О.Б. // Вестн. ПНИПУ. Механика. 2015. № 2. С. 116-126. DOI: $10.15593 /$ perm.mech/2015.2.07

[9] Oborin V., Sokovikov M., Bilalov D., Naimark O., Bachurikhin V. // AIP Conf. Proc. 2016. V. 1785. P. 030019. DOI: $10.1063 / 1.4967040$

[10] Яковлева Т.Ю., Матохнюк Л.Е. // Проблемы прочности. 2004. № 4. C. 145-155.

[11] Билалов Д.А., Баяндин Ю.В., Наймарк О.Б. // Вычислительная механика сплошных сред. 2018. Т. 11. № 3. С. $323-$ 334. DOI: 10.7242/1999-6691/2018.11.3.24 